\section{Improving patient's independence and treating depressive symptoms can promote physical activity in diabetic patients}

\author{
A melhora da independência e o tratamento \\ dos sintomas depressivos podem promover a \\ atividade física em pacientes diabéticos
}

Thiago Medeiros da Costa Daniele', Veralice Meireles Sales Bruin', Débora S. Oliveira', Clara M. Pompeu', Adriana C. Forti'

W e would like to thank Dr. Dinc for the interest in our article suggesting that increasing patient independence and treating depressive symptoms can promote physical activity in type 2 diabetes mellitus patients. Initially, Dr. Dinc and cols. have reaffirmed that community-based studies are highly important. This particular study evaluated diabetic patients from a tertiary care center. We agree that it is important to use scales that have been validated and largely, used as it was done in our study (1). Also, despite the number of controls, data analysis was adequate; however, a greater number of patients and of controls would increase the power of our data. At present, we did not include metabolic status of the patients because this was mainly an analysis of physical activity status, comorbidities, depressive symptoms, and health-related quality of life. We considered that our results, showing a high number of diabetic patients performing physical activity, are valuable because they prove that educational programs are effective. Nevertheless, we know that a lot more needs to be done in order to achieve prevention of metabolic syndrome and diabetes.

In this population, heart failure was not reported and myocardial ischemia and/or previous myocardial infarct were found in $39(20 \%)$ of the cases. As described, these comorbidities were unrelated with physical activity (2). Of note, even low-intensity physical activity has been shown to improve health related measures, particularly cardiovascular function (3). Thus, after safeguarding patients with cardiovascular disorders, advising patients to perform physical activity seems warranted, as a general rule. We think that the need to classify patients according to their cardiac status in order to encourage occasional low-level physical activity could inhibit the encouragement of exercise practice. Of course, physical abilities and comorbidities must be considered for a safe implementation of exercises, and individuals with any indication of cardiovascular disease should be thoroughly evaluated. Recently, a study has shown that a universal strategy to promote physical activity in primary care has the potential to increase the number of years lived free from physical disease (4). The same study affirms that there is only weak evidence that this strategy is cost-effective.

As it has been quoted, depressive symptoms are very frequently associated with diabetes. Interestingly, identified diabetes has been associated with 4 -fold greater odds of depression, while undiagnosed diabetes has not been associated with depression (5). Depressive symptoms are frequent in hemodialysis (6), obstructive sleep apnea
1 Universidade Federal do Ceará (UFC), Fortaleza, CE, Brazil

Correspondence to: Veralice Meireles Sales Bruin veralice@superig.com.br

Received on Apr/25/2013 Accepted on Apr/29/2013 
(7), hypertension (8), and are associated with increased mortality (9). All these clinical situations are frequent in diabetes.

In summary, identifying and treating depressive symptoms in diabetes may improve patient's quality of life and improve adherence to exercise. Physical activity is an important part of effective care and it has been associated with the improvement of restless legs symptoms in these patients (10).

Disclosure: no potential conflict of interest relevant to this article was reported.

\section{REFERENCES}

1. Hallal PC, Simoes E, Reichert FF, Azevedo MR, Ramos LR, Pratt $M$, et al. Validity and reliability of the telephone-administered international physical activity questionnaire in Brazil. J Phys Act Health. 2010;7(3):402-9.

2. Daniele TM, de Bruin VM, de Oliveira DS, Pompeu CM, Forti AC. Associations among physical activity, comorbidities, depressive symptoms and health-related quality of life in type 2 diabetes. Arq Bras Endocrinol Metabol. 2013;57(1):44-50.

3. Merino J, Ferre R, Girona J, Aguas D, Cabré A, Plana N, et al. Even low physical activity levels improve vascular function in overweight and obese postmenopausal women. Menopause. 2013;20(10):1036-42.

4. Gulliford MC, Charlton J, Bhattarai N, Charlton C, Rudisill C. Impact and cost-effectiveness of a universal strategy to promote physical activity in primary care: population-based Cohort study and Markov model. Eur J Health Econ. 2013 Apr 10.

5. Mezuk B, Johnson-Lawrence $V$, Lee H, Rafferty JA, Abdou CM, Uzogara EE, et al. Is ignorance bliss? Depression, antidepressants, and the diagnosis of prediabetes and type 2 diabetes. Health Psychol. 2013;32(3):254-63.

6. Araujo SM, de Bruin VM, Daher Ede F, Almeida GH, Medeiros CA, de Bruin PF. Risk factors for depressive symptoms in a large population on chronic hemodialysis. Int Urol Nephrol. 2012;44(4):1229-35.

7. Farias PAM, Lima AMA, Bruin PFC, Bruin VMS. Sleepdisordered breathing and heavy drinking: clinical features and polysomnographic findings. Sleep Science. 2010;3(4):119-24.

8. Michal M, Wiltink J, Lackner K, Wild PS, Zwiener I, Blettner $M$, et al. Association of hypertension with depression in the community: results from the Gutenberg Health Study. J Hypertens. 2013;31(5):893-9.

9. Teng PR, Yeh CJ, Lee MC, Lin HS, Lai TJ. Depressive symptoms as an independent risk factor for mortality in elderly persons: results of a national longitudinal study. Aging Ment Health. 2013;17(4):470-8.

10. Daniele TM, de Bruin VM, AC EF, de Oliveira DS, Pompeu CM, de Bruin PF.The relationship between physical activity, restless legs syndrome, and health-related quality of life in type 2 diabetes. Endocrine. 2013;44(1):125-31. 